\title{
Intellectual property rights in Africa: The way ahead
}

\section{BOOK TITLE:}

Innovation \& intellectual property: Collaborative dynamics in Africa

\section{BOOK COVER:}

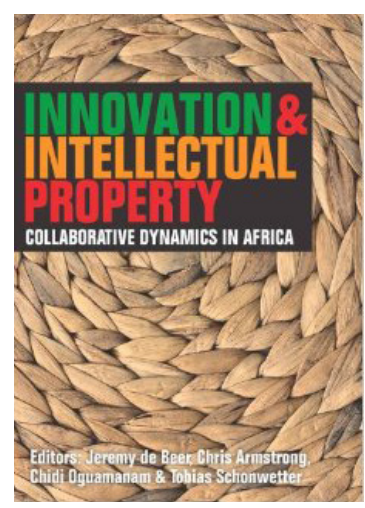

\section{EDITORS:}

Jeremy de Beer, Chris Armstrong, Chidi Oguamanam,

Tobias Schonwetter

ISBN:

9781919895994 (softcover)

\section{PUBLISHER:}

Open A-I-R, UCT Press, Cape Town, ZAR350 (the electronic version is licensed under a Creative Commons licence)

\section{PUBLISHED:}

2014

\section{REVIEW TITLE:}

Intellectual property rights in Africa: The way ahead

\section{REVIEWER:}

Anastassios Pouris

\section{EMAIL:}

Anastassios.Pouris@up.ac.za

\section{AFFILIATION:}

Institute for Technological Innovation, University of Pretoria, Pretoria, South Africa

\section{POSTAL ADDRESS:} Institute for Technological Innovation, University of Pretoria, Private Bag X20, Hatfield 0028, South Africa

\section{HOW TO CITE:}

Pouris A. Intellectual property rights in Africa: The way ahead. S Afr J Sci. 2015;111(7/8), Art. \#a0111, 1 page. http://dx.doi. org/10.17159/sajs.2015/a0111
This book was produced by the Open African Innovation Research and Training Project which is a research and training network aimed at raising intellectual property (IP) awareness in Africa and facilitates critical policy engagements including the identification of relevant bottlenecks and the interrogation of innovation metrics and structures. The Project is supported financially by Canada's IDRC and Germany's BMZ.

The editors of the book are associated with the Universities of Ottawa, the Witwatersrand and Cape Town. The contributing authors responded to an open public call to investigate issues related to the question: How can existing or potential IP systems be harnessed to appropriately value and facilitate innovation and creativity for open development in Africa? The themes covered by the book include patents, copyrights, publicly funded research, trademarks, geographic indications, traditional knowledge and informal appropriations.

The book - 408 pages - covers mainly case studies in nine African countries: Botswana, Egypt, Ethiopia, Ghana, Kenya, Nigeria, Mozambique, South Africa and Uganda. Most of the case studies are localised in nature. Chapter 10 (African Patent Offices not fit for purpose) is the only paper covering the continent extensively. It reports on the capacities of patent offices in 44 countries in Africa. Professor Mgbeoji found that most of the national patent offices on the continent were ill equipped to discharge their two main functions: examining patent applications and collating patent information so that it can be made publicly available for public and inventor follow-on use.

The authors state that 'the book makes no claim to be comprehensive' ( $p .15)$. The final chapter is a summary of the findings of collaborative innovation and creativity, openness and intellectual property. There are 'vibrant collaborative models at play in relation to innovation and livelihood development' (p.388), but they range from the extremely informal to considerably more formal. Similarly, the case studies show that open development cannot be conceived as a binary proposition - either open or closed.

As far as IP is concerned, the editors suggest that:

Policymakers and actors will need to move away from dominant preconceptions of IP involving mainly patent, copyright and trademark protections. Informal and flexible protections such as trade secrets seem much better suited to the informal sector. (p.389)

Finally, the editors identify that although IP laws are in place, their impact is minimal because of shortcomings in the administrative structure needed to implement and enforce these laws.

The book develops three recommendations for African policymakers. The first recommendation is to avoid mistakes. The editors suggest that not having an IP policy may be better than entrenching the wrong IP policy. The second recommendation is to broaden conceptions of relevant and valuable IP practices. The editors suggest that 'patent systems are irrelevant to many of the modes of innovation and creativity happening in Africa' (p.392). They suggest that informal modes of IP protection, such as trade secrecy, may be better suited to Africa's environment. Similarly, they suggest that branding may be a useful form of IP in many instances. Finally, the suggestion is developed that African policymakers need to look forwards not backwards. It is stated that 'going forward, African policymakers, as with the innovators and creators whom the policymakers are supposed to serve, must seek to harness IP rights on their own terms'.

It is important to notice that the book aimed to answer certain questions by interrogating mainly African experts and practitioners. However, a broader view could provide additional useful information for advice. For example, IP laws are imposed on Africa and other developing countries by outside forces. Starting in the 1980s, the USA imposed strong pressure on developing countries with weak IP laws and institutions through its 'Special 301' provision of the US trade law. Countries threatened with sanctions are forced to strengthen their patent laws. Countries like China, Indonesia, Taiwan and Malaysia were forced in the 1980s and 1990s to introduce patent laws related to pharmaceuticals.

It should also be emphasised that the non-examining approaches followed in Africa are facilitating their exploitation by foreigners who are able to protect their ideas even when they are not patentable. Pouris ${ }^{1}$, investigating the South African patent system, argued that 'granting patents for inventions that are not new or useful or that are obvious, unjustly rewards the patent holder at the expense of real inventors, the consumer and social welfare'. African countries need to get out of the current method of non-examining approaches.

Finally, the suggestion that policymakers should look forward may be misunderstood. History usually provides valuable lessons for the future. For example, Chang ${ }^{2}$ suggests that the developed countries refused to institutionalise patent regimes when they were in the development stage.

The book makes a valuable contribution in a neglected field in Africa and undoubtedly will attract considerable debate.

\section{References}

1. Pouris A, Pouris A. Patents and economic development in South Africa: Managing intellectual property rights. S Afr J Sci. 2011;107(11/12):24-33. http://dx.doi.org/10.4102/sajs.v107i11/12.355

2. Chang HJ. Bad samaritans: The myth of free trade and the secret history of capitalism. New York: Bloomsbury Press; 2008. 